\title{
The Relevance of the Use of Radiographic Planning in Order to Avoid Complications in Mandibular Implantology: A Retrospective Study
}

\author{
Gilberto Sammartino, ${ }^{1}$ Juan Carlos Prados-Frutos, ${ }^{2}$ Francesco Riccitiello, ${ }^{1}$ Pietro Felice, ${ }^{3}$ \\ Vincenzo Cerone, ${ }^{1}$ Roberta Gasparro, ${ }^{1}$ and Hom-Lay Wang ${ }^{4}$
}

${ }^{1}$ Department of Neuroscience, Reproductive Sciences and Odontostomatology, University of Naples, Via Pansini 5, Edificio 14, 80131 Naples, Italy

${ }^{2}$ Stomatology Department, Rey Juan Carlos University, Madrid, Spain

${ }^{3}$ Department of Periodontology and Implantology, University of Bologna, Bologna, Italy

${ }^{4}$ School of Dentistry, University of Michigan, Ann Arbor, MI, USA

Correspondence should be addressed to Roberta Gasparro; roberta.gasparro88@gmail.com

Received 21 December 2015; Revised 17 March 2016; Accepted 11 April 2016

Academic Editor: Ayhan Cömert

\begin{abstract}
Copyright (C) 2016 Gilberto Sammartino et al. This is an open access article distributed under the Creative Commons Attribution License, which permits unrestricted use, distribution, and reproduction in any medium, provided the original work is properly cited.

The aim of this retrospective radiological study was to evaluate the variability of the mandibular anatomy in the presence and absence of teeth and to consider how it could influence implant planning. 187 mandibular CT DentaScans were selected from our department archive according to the inclusion criteria. The axial height, vertical height, angulation of the bone crest, and the bone available for ideal implant placement were measured. The analysis of the data shows that the mandible contour presents a constant degree of angulation. The variation of angulation in the absence of teeth was statistically significant only in the region between the canine and the first premolar and in that between the second premolar and the first molar. The difference between the crest height and the available distance to place the implant was greater in the region of the second molar while in the other regions the implant planning was made complex by postextraction resorption. Alveolar bone resorption after tooth loss can be considered as a risk factor for lingual cortical perforation during the insertion of an implant. To avoid potential intra/postoperative complications, 3D radiographic examination is recommended in order to study the mandibular anatomy and identify the risk areas.
\end{abstract}

\section{Introduction}

For a better implant placement and to avoid surgical complications, clinicians must have total knowledge of the bone anatomy, including the osseous topography, bone volume, crest angulation, and bone deficiencies $[1,2]$. To obtain this information, as well as the clinical examination, a radiographic study of the jaw anatomy is essential. A variety of imaging modalities is available for preoperative planning purposes [3]. Computed Tomography (CT), in the past, and Cone Beam Computed Tomography (CBCT), nowadays, seem to be the best presurgical radiographic evaluations for the prevention of complications related to an incorrect implant placement, either mechanical, esthetic, or surgical.
Mechanical complications are caused by the necessity of using angled abutments to correct the implant axis, which results in a bending movement of the implant and potential biomechanical problems [4]. Types of failure relating to angled abutments include fractures of the coating material [5], fractures in parts of the framework [5], loosening of the abutment screws $[4,5]$, and loss of implant osseointegration $[5,6]$. Surgical complications may occur during or immediately after the surgery. They mainly consist in damage to the neurovascular structures close to the implant site [7]. Generally, dental implant positioning in the interforaminal region of an edentulous mandibular ridge is considered a safe surgical procedure [8-10]. The arterial blood supply to the mouth floor is formed by an anastomosis between 
the sublingual artery ( $2 \mathrm{~mm}$ in average diameter), a branch of the lingual artery, and the submental artery $(2 \mathrm{~mm}$ in average diameter), a branch of the facial artery [11, 12], which passes close to the lingual plate. Intraosseous hemorrhage is not a serious event and its control can be ensured by compressing the area with an implant, for example [12].

Severe bleeding and the formation of massive hematomas in the floor of the mouth are the result of an arterial trauma. A hemorrhage noted in the mandibular floor of the mouth during or after implant surgery is caused, in most cases, by a perforation of the lingual cortical plate [13]. Goodacre et al. found hemorrhage as a complication of implant surgery placement with an incidence of up to $24 \%$ [14]. This occurrence may lead to extensive bleeding into the submandibular area, resulting in a life-threatening acute airway obstruction within the first few hours after surgery [15]. The hemorrhage can easily spread into the loose tissues of the floor of the mouth, the sublingual area, and the space between the lingual muscles, which may require intubation or an emergency tracheostomy [14].

In the posterior mandibular region, major complications are related to damage to the inferior alveolar nerve as well as the mylohyoid artery, a branch of the inferior alveolar artery. The lingual concavity (submandibular gland fossa and submandibular fossa) below the mylohyoid ridge, with its variations, could restrict the implant placement [16].

The alveolar bone crest is subject to vertical and horizontal resorption secondary to tooth loss; this may cause an increased incidence of complications during implant surgery. To avoid these potential complications, an anatomical study of the mandible and its variability is necessary. To perform a 3-dimensional (3D) study of the mandibular bone morphology and to obtain a millimeter $(\mathrm{mm})$ scale read on the vertical and horizontal measurements, CT dental scan examination has become popular [17]. Hence, the aim of this retrospective radiological study was to evaluate the variability of the mandibular anatomy in the presence and absence of teeth and to consider how it could influence implant planning.

\section{Materials and Methods}

2.1. CT Selection. Two hundred and twenty-six (out of 513) images \{124 males and 102 females; mean age: $45.24 \pm$ 12.86 (range: 18-70)\} from the radiographic archive of the Department of Oral Surgery of the University of Naples Federico II that met the following inclusion criteria were obtained:

(i) A good quality of the CT images (clear, well defined, without any artifacts and interference due to previous treatment such as dental implants, crowns, or pontics).

(ii) An analogical CT presenting a reference plane parallel to the occlusal plane in mandibles with teeth or parallel to the mandibular lower margin in edentulous mandibles and/or a digital $\mathrm{CT}$ which provides an original DICOM file (gantry tilt $=0^{\circ}$ ).

(iii) The presence of teeth in the dental arch or the absence of teeth in the dental arch with a minimum

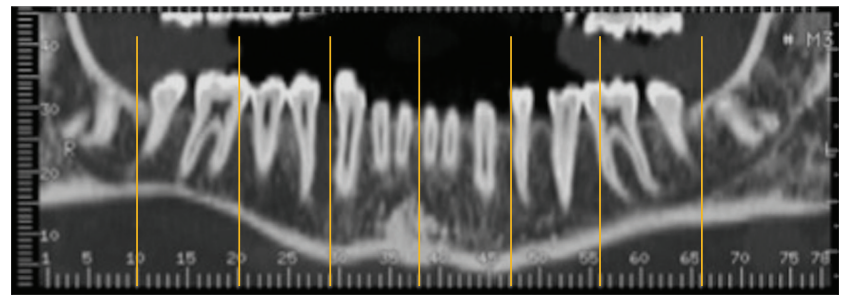

FIGURE 1: Regions of interest.

residual height of $10 \mathrm{~mm}$ from the alveolar canal and a minimum ridge width of $6 \mathrm{~mm}$, excluding severe atrophies.

(iv) An orthoradial section of $2 \mathrm{~mm}$.

(v) The absence of pathological or traumatic conditions that might modify the anatomical mandibular morphology.

As the CTs came from different radiological centers, it was hypothesized that the parameters of the patient positioning, exposure, and reconstruction algorithms would be different. Therefore, the CTs were grouped according to the radiological centers, excluding those centers that did not provide a sufficient number of CT scans for the statistical analysis, resulting in a total number of 187 CTs (92 males and 95 females; mean age: $46.78 \pm 14.36$; age range: $18-70$ ). Finally, given that the measurements for each center were similar to each other, they were grouped into a single sample.

Informed consent was obtained from all patients.

This study has been approved by the Ethical Committee of the University of Naples Federico II.

2.2. Procedure. The analogical CT images were digitalized using an Epson Perfection 4990 scanner (Seiko Epson Corporation, Suwa, Nagano, Japan). All the digital CTs were postprocessed to obtain a gantry tilt $=0^{\circ}$. All the measurements were performed on orthoradial sections by a single implantologist (RG) using the digital program OsiriX 5.8.2 for Mac OS X that is recommended for preoperative planning [18]. For each sample, in the presence of teeth, it was decided to perform the measurements in different regions (Figure 1):

(i) The symphysis region that corresponds to the section between the two central incisors.

(ii) The region between the canine and first premolar on the right and left.

(iii) The region between the second premolar and the first molar on the right and left.

(iv) The region on the distal margin or distal root of the second molar on the right and left.

In CTs without teeth, the section between the apophysis genii was considered as the median one. The other measurements were chosen after measuring the mean distance of the areas considered in the CT with teeth with respect to the central 


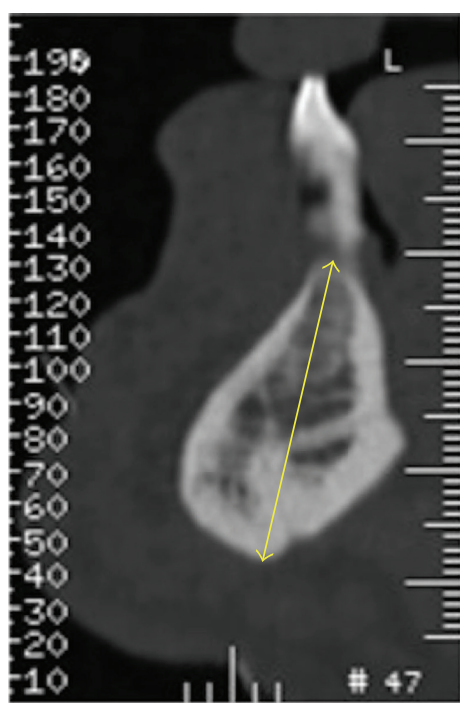

(a)

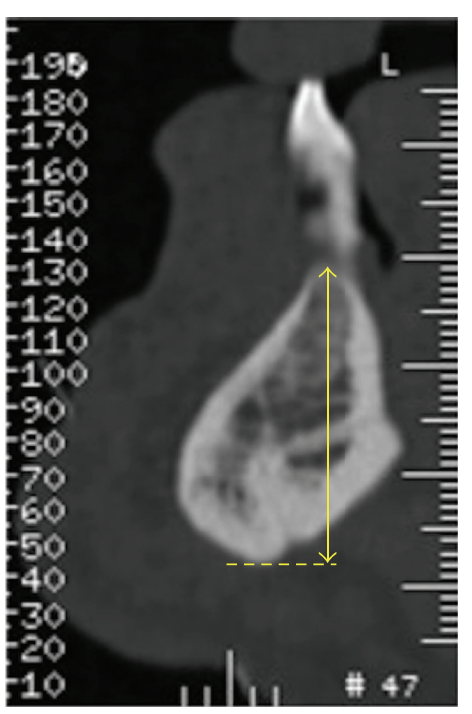

(b)

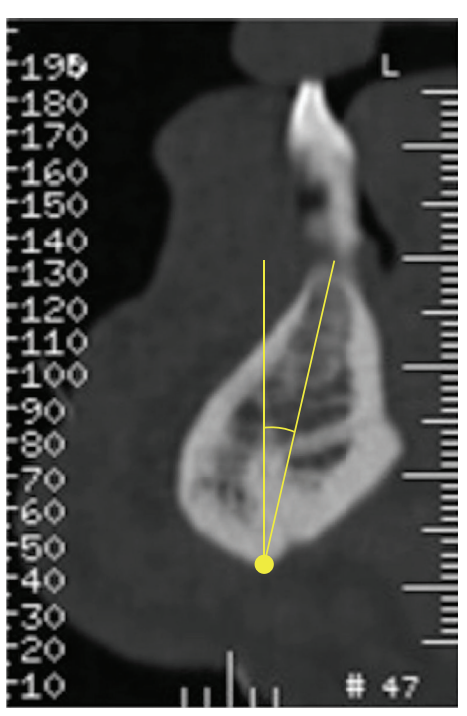

(c)

FIgURE 2: (a) The distance between the most coronal and medial point of the ridge and the lowest point along the axis of the crest; (b) the height from the most coronal and medial point of the ridge to the projection of the lowest point on the perpendicular to the CT reference plane; (c) the angle between the axis of the crest and the line perpendicular to the CT reference plane.

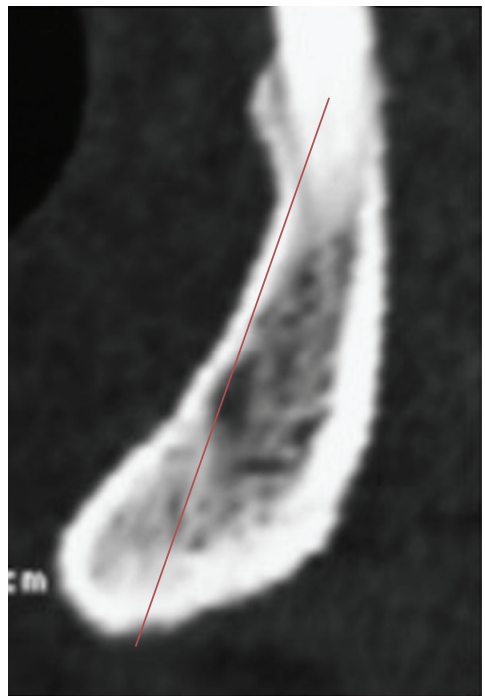

(a)

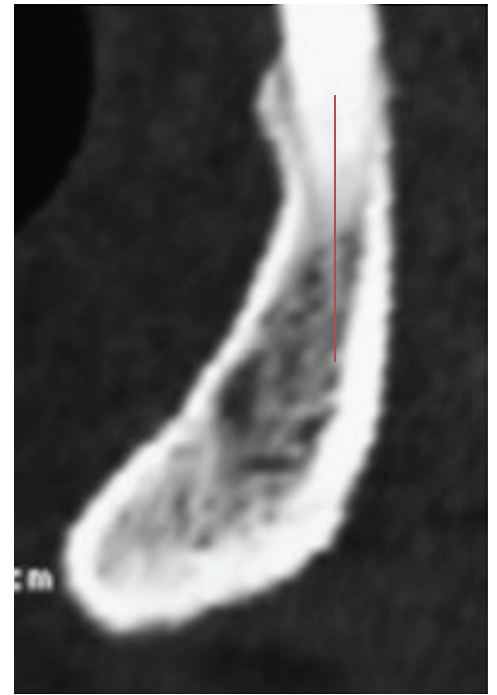

(b)

Figure 3: (a) The distance between the most coronal and medial point of the ridge and the lowest point along the axis of the crest; (b) the available distance to place the implant.

section. For each region, the following measurements were observed: the axial height, vertical height, and angulation (Figures 2(a), 2(b), and 2(c)). In the interforaminal region, the axial height and the available distance to place the implant were compared (Figures 3(a) and 3(b)).

In the posterior region of the mandible, considering a safety distance of $1.5 \mathrm{~mm}[19,20]$, the distance from the most coronal medial point of the ridge to the inferior alveolar nerve was compared with the available distance for implant positioning (Figures 4(a) and 4(b)).
The available distance in both regions was chosen by one single expert implantologist as the maximum distance to place the implant according to an axis of insertion that realistically is close to the ideal one. Finally, given that the measurements for each sample were similar to each other, they were grouped into a single sample. Except for the symphysis region, the right and left sites of each region were combined into one single sample.

2.3. Statistical Analysis. The statistical analysis was performed using the statistical software package IBM SPSS 
TABLE 1: Angulation means revealing statistically significant difference between the canine-first premolar region and second premolar-first molar region relating to the presence or absence of teeth.

\begin{tabular}{lccc}
\hline & Presence of teeth & Absence of teeth & $P$ value \\
\hline Symphysis & $(n=111) 9.26 \pm 6.63$ & $(n=76) 11.07 \pm 8.84$ & 0.374 \\
Canine-first premolar & $(n=270) 7.43 \pm 4.77$ & $(n=104) 10.96 \pm 4.99$ & 0.000632 \\
Second premolar-first molar & $(n=252) 9.38 \pm 5.38$ & $(n=122) 12.49 \pm 5.94$ & 0.000617 \\
Distal site of second molar & $(n=178) 16.06 \pm 5.99$ & $(n=196) 16.37 \pm 7.47$ & 0.768 \\
\hline
\end{tabular}

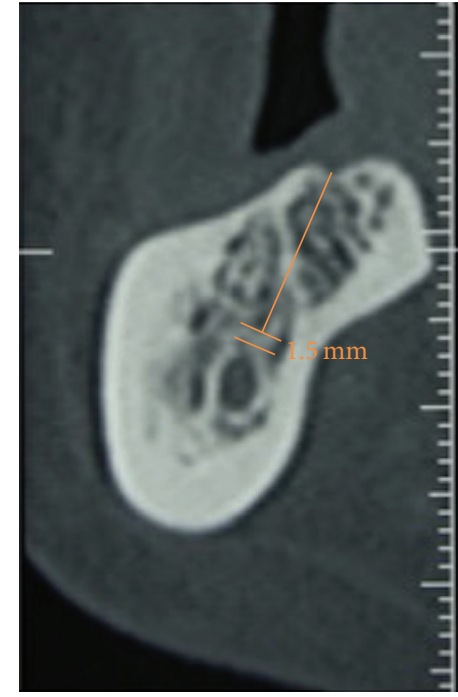

(a)

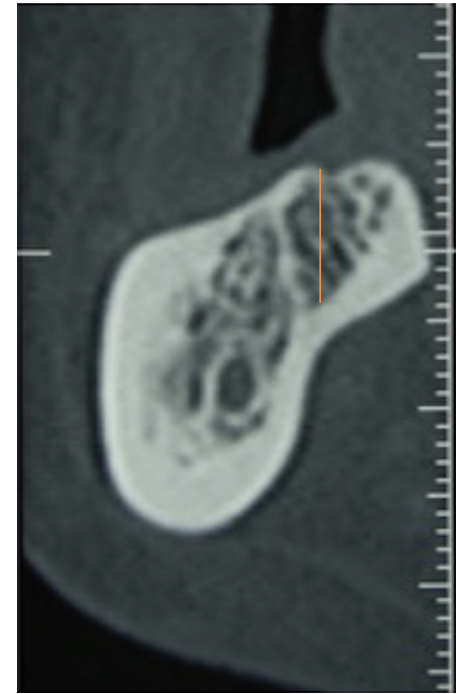

(b)

Figure 4: (a) The distance from the most coronal and medial point of the ridge to the inferior alveolar nerve; (b) the available distance for implant positioning.

Statistics for Windows, version 21.0 (Released 2012, IBM Corp., Armonk, NY, USA).

\section{Results}

One hundred and eighty-seven mandibular CTs (92 males and 95 females; mean age: $46.78 \pm 14.36$; age range: $18-70$ ) were evaluated. The mandible presents a constant degree of angulation in the buccolingual direction and from the bottom upwards. The lowest degree of mandibular angulation was between the canine and first premolar in both groups (in the presence of teeth: mean $7.43^{\circ} \pm 4.77^{\circ}$; in the absence of teeth: mean $\left.10.96 \pm 4.99^{\circ}\right)$. Therefore, the highest value was at the distal point of the second molar in both groups (in the presence of teeth: mean $16.06^{\circ} \pm 5.99^{\circ}$; in the absence of teeth: mean $16.37^{\circ} \pm 7.47^{\circ}$ ).

The mean angulation of the jaw in the samples examined in the absence of teeth is greater than in the presence of teeth in all the considered regions but the difference is statistically significant only in the region between the canine and first premolar and between the second premolar and the first molar (Table 1). There is no statistically significant difference in the angulation between women and men.

The difference between the axial height and the available distance to place the implant, considering the symphysis, is
TABLE 2: Difference between the axial height and the available distance at the level of symphysis revealing similarity in both groups (presence or absence of teeth).

\begin{tabular}{lcc}
\hline & Presence of teeth & Absence of teeth \\
\hline Axial height & $28.23 \pm 5.32$ & $26.84 \pm 4.67$ \\
Available distance & $24.54 \pm 4.73$ & $22.90 \pm 3.78$ \\
\hline Difference & 3.69 & 3.94
\end{tabular}

TABle 3: Difference between the axial height and the available distance at the level of the canine-first premolar.

\begin{tabular}{lcc}
\hline & Presence of teeth & Absence of teeth \\
\hline Axial height & $27.12 \pm 3.62$ & $24.22 \pm 4.13$ \\
Available distance & $23.45 \pm 4.50$ & $19.66 \pm 3.93$ \\
\hline Difference & 3.67 & 5.30 \\
\hline
\end{tabular}

similar in both groups (Table 2). In the canine-first premolar region, more differences were observed between the values: in the presence of teeth: mean $3.67 \mathrm{~mm}$; in the absence of teeth: mean $5.30 \mathrm{~mm}$ (Table 3).

Studying the posterior region, in the presence of teeth, the difference between the nerve distance and the available distance is greater in the distal site of the second molar (mean 
TABLE 4: (a) Difference between the nerve distance and the available distance in the presence of teeth. (b) Difference between the nerve distance and the available distance in the absence of teeth.

(a)

\begin{tabular}{lccc}
\hline & $\begin{array}{c}\text { Distance from } \\
\text { the nerve } \\
(\mathrm{mm})\end{array}$ & $\begin{array}{c}\text { Available } \\
\text { distance }(\mathrm{mm})\end{array}$ & Difference \\
\hline $\begin{array}{l}\text { Regions 5-6 (252 } \\
\text { samples) }\end{array}$ & $16.94 \pm 4.17$ & $14.83 \pm 3.55$ & 2.11 \\
$\begin{array}{l}\text { Region 7 (178 } \\
\text { samples) }\end{array}$ & $15.10 \pm 3.93$ & $12.64 \pm 4.21$ & 2.46 \\
\hline
\end{tabular}

(b)

\begin{tabular}{lccc}
\hline & $\begin{array}{c}\text { Distance from } \\
\text { the nerve } \\
(\mathrm{mm})\end{array}$ & $\begin{array}{c}\text { Available } \\
\text { distance } \\
(\mathrm{mm})\end{array}$ & Difference \\
\hline $\begin{array}{l}\text { Regions 5-6 (122 } \\
\text { samples) }\end{array}$ & $14.32 \pm 3.45$ & $12.16 \pm 3.56$ & 2.16 \\
$\begin{array}{l}\text { Region 7 (196 } \\
\text { samples) }\end{array}$ & $12.6 \pm 4.11$ & $10.44 \pm 3.72$ & 2.16 \\
\hline
\end{tabular}

$2.46 \mathrm{~mm}$ ) than in the second premolar-first molar region (mean $2.11 \mathrm{~mm}$ ) (Table 4(a)). There is no difference between the two regions when the teeth are absent (Table $4(\mathrm{~b})$ ).

\section{Discussion}

Influencing factors, such as the buccolingual, apicocoronal, and mesiodistal 3D positions as well as the implant angulation, dictate a correct implant placement [21]. The ideal implant position must be predetermined according to the future prosthesis, occlusal plane, and esthetic parameters. Mandibular teeth, in the natural dentition, have a slight lingual inclination in relation to both the mandibular base [22] and the opposite maxillary arch dentition, and therefore implants should be placed considering both inclinations [23].

The results from our study showed that the mandibular angulation was $7.43^{\circ} \pm 4.77^{\circ}$ in the presence of teeth and $10.96^{\circ} \pm 4.99^{\circ}$ when the teeth were absent between the canine and first premolar. The same trend was also noted in the second premolar-first molar area. As presented, we noticed a major change of angulation, in the sense that the axial height and available distance were different from each other. This sets a restriction on the implant positioning according to an ideal prosthetic axis, limiting the use of angled abutments.

Angled abutments result in an increased stress on the implants and adjacent teeth [24]. When the abutment angulation increased, the stress and strain increased [25]. Although Sethi et al. reported that the magnitude of the angles did not significantly influence the overall implant survival rate [26], the stresses on the bone might go beyond physiological limits when the abutments are angled [27].

The anatomy of the mandible is different in the presence and absence of teeth and changes, due to the bone remodeling after tooth loss leading to a variation of the bone height, width, and angle, may complicate the surgical act of the implant placement [28]. Initially, the greatest amount of bone
TABLE 5: The proposed classification of mandibular angulation based upon the potential risk of lingual plate perforation.

\begin{tabular}{lcc}
\hline & Angle & Risk assessment \\
\hline LMI & $<10^{\circ}$ & Low risk \\
MMI & $10^{\circ}<$ angle $<17^{\circ}$ & Medium risk \\
HMI & $>17^{\circ}$ & High risk \\
\hline
\end{tabular}

loss is in the horizontal dimension and occurs mainly on the buccal plate of the ridge. Our results, which consist in increased mandibular angulation in each considered region, are confirmed by the literature, which shows more buccal resorption and lingual relocation of the ridge [29]. These changes seem to be more evident in the middle regions of the mandibular body.

Although the area of second molar is not affected by excessive changes, overangulation, as mentioned before, may increase the difficulty in achieving an optimal implant placement. In the symphysis region, not having excessive angulation or an excessive modification of height and angulation after tooth loss, the axial height and available distance are similar in both groups, rendering this region a safety area, if a careful evaluation of the anatomical characteristics of the lingual plate has already been performed.

Some authors have even suggested that a CT scan should be performed routinely before implant placement in the interforaminal region [30].

In terms of image quality, reproducibility, and validity, the CBCT produced superior images to the helical CT, with approximately 400-fold less radiation exposure in the dental radiology field [31-33].

Another advantage is accuracy $[1,33]$ because the CBCT volumetric data is isotropic. This makes it possible to reorient the images to fit the patient's anatomical features and to perform real-time measurements [33, 34].

CBCT units provide choices in terms of field of view (FOV), which allows irradiation of particular areas of interest to dentists, while limiting the irradiation of other tissues. This function contributes to an excellent resolution and a minimal radiation risk for the patients $[33,35,36]$.

One major disadvantage is that it can only demonstrate a limited contrast resolution $[33,37,38]$. If the objective of the examination is hard tissue only, using a CBCT would not be a problem; however, it is not sufficient for soft tissue evaluation $[33,39]$.

According to our measurements, it was possible to propose a classification of mandible angles based on the potential risk of lingual cortical plate perforation (Table 5):

(i) Low mandibular inclination (LMI): angle $<10^{\circ}$.

(ii) Medium mandibular inclination (MMI): angle between $10^{\circ}$ and $17^{\circ}$.

(iii) High mandibular inclination (HMI): angle $>17^{\circ}$.

One of the most important clinical applications of our study concerns postextraction implants; in these cases, clinicians usually believe that the transversal dimension is sufficient, given the postextractive nature of the implant. Moreover, 


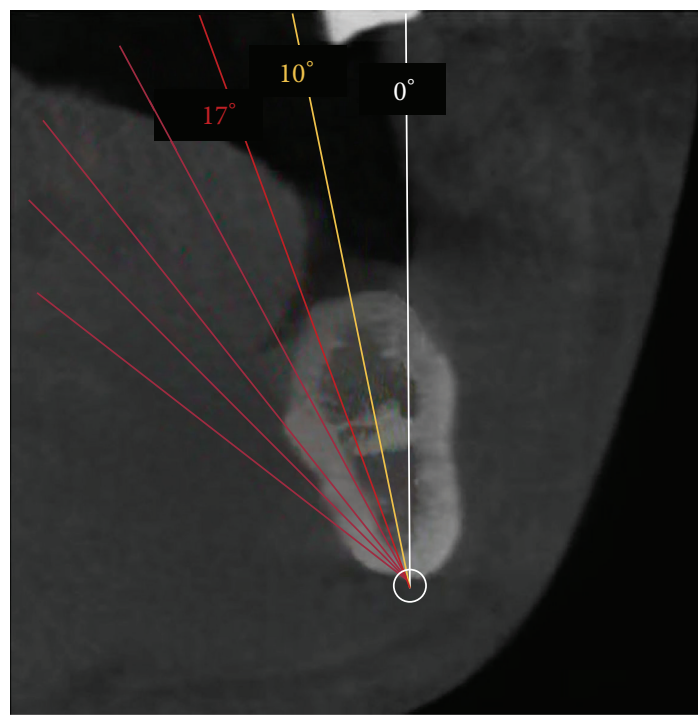

Figure 5: Different ranges of angulation.

clinicians assume that the vertical dimension can be calculated by using a panoramic radiograph, with a template to overcome the related distortion, adding at least $2 \mathrm{~mm}$ beyond the alveolar socket in order to achieve an optimal primary stability [40]. However, in the presence of high alveolar crest angulation, there is an increased risk of lingual plate perforation (Figure 5) which may trigger clinical complications.

Even today, many dentists in immediate postextractive implantology believe that the vertical dimension is present within the two-dimensionality of the OPT. However, due to the variability of the mandibular anatomy, CBCT, nowadays, is recommended for safer presurgery planning.

\section{Conclusions}

To prevent unintentional hemorrhages, in cases involving immediate placement, practitioners are recommended not to use the extraction socket as a guide for angulation. Alveolar bone resorption after tooth loss can be considered as a risk factor for lingual cortical perforation during the insertion of an implant. Presurgical implant planning is not possible without a proper study of a $3 \mathrm{D}$ radiographic examination that allows the clinician to study the mandibular anatomy and identify the risk areas.

\section{Additional Points}

The aim of this study was to evaluate the variability of the mandibular anatomy in the presence and absence of teeth and to consider how it could influence implant planning. The mandibular anatomy variability, due to the jaw angulation, presents challenges to the surgeon in the placing of the implant safely. To avoid any potential intra/postoperative complications, high precision radiography is recommended for better presurgery planning.

\section{Competing Interests}

The authors declare that there are no competing interests regarding the publication of this paper.

\section{References}

[1] T. Razavi, R. M. Palmer, J. Davies, R. Wilson, and P. J. Palmer, "Accuracy of measuring the cortical bone thickness adjacent to dental implants using cone beam computed tomography," Clinical Oral Implants Research, vol. 21, no. 7, pp. 718-725, 2010.

[2] G. Greenstein, J. Cavallaro, G. Romanos, and D. Tarnow, "Clinical recommendations for avoiding and managing surgical complications associated with implant dentistry: A review," Journal of Periodontology, vol. 79, no. 8, pp. 1317-1329, 2008.

[3] R. Jacobs, "Preoperative radiologic planning of implant surgery in compromised patients," Periodontology 2000, vol. 33, pp. 1225, 2003.

[4] L. Al-Faraje, Surgical Complications in Oral Implantology: Etiology, Prevention, and Management, Quintessence, Hanover Park, Ill, USA, 2011.

[5] T. J. Balshi, A. Ekfeldt, T. Stenberg, and L. Vrielinck, “Threeyear evaluation of Brånemark implants connected to angulated abutments," The International Journal of Oral \& Maxillofacial Implants, vol. 12, pp. 52-58, 1997.

[6] D. E. Eger, J. C. Gunsolley, and S. Feldman, "Comparison of angled and standard abutments and their effect on clinical outcomes: a preliminary report," International Journal of Oral and Maxillofacial Implants, vol. 15, no. 6, pp. 819-823, 2000.

[7] L. Ardekian and T. B. Dodson, "Complications associated with the placement of dental implants," Oral and Maxillofacial Surgery Clinics of North America, vol. 15, no. 2, pp. 243-249, 2003.

[8] C. D. Kalpidis and A. B. Konstantinidis, "Critical hemorrhage in the floor of the mouth during implant placement in the first mandibular premolar position: a case report," Implant Dentistry, vol. 14, no. 2, pp. 117-124, 2005.

[9] L. Dubois, J. de Lange, E. Baas, and J. Van Ingen, "Excessive bleeding in the floor of the mouth after endosseus implant placement: a report of two cases," International Journal of Oral and Maxillofacial Surgery, vol. 39, no. 4, pp. 412-415, 2010.

[10] B. M. Woo, S. Al-Bustani, and B. A. Ueeck, "Floor of mouth haemorrhage and life-threatening airway obstruction during immediate implant placement in the anterior mandible," International Journal of Oral and Maxillofacial Surgery, vol. 35, no. 10, pp. 961-964, 2006.

[11] M. S. Scaravilli, M. Mariniello, and G. Sammartino, "Mandibular lingual vascular canals (MLVC): evaluation on dental CTs of a case series," European Journal of Radiology, vol. 76, no. 2, pp. 173-176, 2010.

[12] S. Annibali, M. Ripari, G. La Monaca, F. Tonoli, and M. P. Cristalli, "Local accidents in dental implant surgery: prevention and treatment," The International Journal of Periodontics \& Restorative Dentistry, vol. 29, no. 3, pp. 325-331, 2009.

[13] H.-J. Nickenig, M. Wichmann, S. Eitner, J. E. Zöller, and M. Kreppel, "Lingual concavities in the mandible: a morphological study using cross-sectional analysis determined by CBCT," Journal of Cranio-Maxillofacial Surgery, vol. 43, no. 2, pp. 254259, 2015.

[14] C. J. Goodacre, G. Bernal, K. Rungcharassaeng, and J. Y. K. Kan, "Clinical complications with implants and implant prostheses," Journal of Prosthetic Dentistry, vol. 90, no. 2, pp. 121-132, 2003. 
[15] C. D. R. Kalpidis and R. M. Setayesh, "Hemorrhaging associated with endosseous implant placement in the anterior mandible: a review of the literature," Journal of Periodontology, vol. 75, no. 5, pp. 631-645, 2004.

[16] M.-H. Lin, L.-P. Mau, D. L. Cochran, Y.-S. Shieh, P.-H. Huang, and R.-Y. Huang, "Risk assessment of inferior alveolar nerve injury for immediate implant placement in the posterior mandible: a virtual implant placement study, Journal of Dentistry, vol. 42, no. 3, pp. 263-270, 2014.

[17] R. Jacobs, A. Adriansens, K. Verstreken, P. Suetens, and D. Van Steenberghe, "Predictability of a three-dimensional planning system for oral implant surgery," Dentomaxillofacial Radiology, vol. 28, no. 2, pp. 105-111, 1999.

[18] O. S. Júnior, L. R. Pinheiro, O. S. Umetsubo, M. A. O. Sales, and M. G. P. Cavalcanti, "Assessment of open source software for CBCT in detecting additional mental foramina," Brazilian Oral Research, vol. 27, no. 2, pp. 128-135, 2013.

[19] G. Sammartino, G. Marenzi, R. Citarella, R. Ciccarelli, and H.-L. Wang, "Analysis of the occlusal stress transmitted to the inferior alveolar nerve by an osseointegrated threaded fixture," Journal of Periodontology, vol. 79, no. 9, pp. 1735-1744, 2008.

[20] G. Sammartino, H.-L. Wang, R. Citarella, M. Lepore, and G. Marenzi, "Analysis of occlusal stresses transmitted to the inferior alveolar nerve by multiple threaded implants," Journal of Periodontology, vol. 84, no. 11, pp. 1655-1661, 2013.

[21] A. P. Saadoun, M. LeGall, and B. Touati, "Selection and ideal tridimensional implant position for soft tissue aesthetics," Practical Periodontics and Aesthetic Dentistry, vol. 11, no. 9, pp. 1063-1074, 1999.

[22] Gray H Gray's Anatomy, Churchill Livingstone, Edinburgh, Scotland, 1980.

[23] K. Misch and H.-L. Wang, "Implant surgery complications: etiology and treatment," Implant Dentistry, vol. 17, no. 2, pp. 159$168,2008$.

[24] J. Cavallaro Jr. and G. Greenstein, "Angled implant abutments: a practical application of available knowledge," Journal of the American Dental Association, vol. 142, no. 2, pp. 150-158, 2011.

[25] T. Brosh, R. Pilo, and D. Sudai, "The influence of abutment angulation on strains and stresses along the implant/bone interface: comparison between two experimental techniques," The Journal of Prosthetic Dentistry, vol. 79, no. 3, pp. 328-334, 1998.

[26] A. Sethi, T. Kaus, P. Sochor, D. Axmann-Krcmar, and M. Chanavaz, "Evolution of the concept of angulated abutments in implant dentistry: 14-year clinical data," Implant Dentistry, vol. 11, no. 1, pp. 41-51, 2002.

[27] R. Martin, Structure, Function, and Adaptation of Compact Bone, Raven Press, New York, NY, USA, 1989.

[28] U. Covani, M. Ricci, G. Bozzolo, F. Mangano, A. Zini, and A. Barone, "Analysis of the pattern of the alveolar ridge remodelling following single tooth extraction," Clinical Oral Implants Research, vol. 22, no. 8, pp. 820-825, 2011.

[29] F. Van der Weijden, F. Dell'Acqua, and D. E. Slot, "Alveolar bone dimensional changes of post-extraction sockets in humans: a systematic review," Journal of Clinical Periodontology, vol. 36, no. 12, pp. 1048-1058, 2009.

[30] R. J. Miller, W. C. Edwards, C. Boudet, and J. H. Cohen, "Maxillofacial anatomy: the mandibular symphysis," Journal of Oral Implantology, vol. 37, no. 6, pp. 745-753, 2011.

[31] K. Hashimoto, S. Kawashima, S. Kameoka et al., "Comparison of image validity between cone beam computed tomography for dental use and multidetector row helical computed tomography," Dentomaxillofacial Radiology, vol. 36, no. 8, pp. 465-471, 2007.

[32] K. Hashimoto, S. Kawashima, M. Araki, K. Iwai, K. Sawada, and Y. Akiyama, "Comparison of image performance between cone-beam computed tomography for dental use and four-row multidetector helical CT," Journal of Oral Science, vol. 48, no. 1, pp. 27-34, 2006.

[33] S. Adibi, W. Zhang, T. Servos, and P. N. O’Neill, “Cone beam computed tomography in dentistry: what dental educators and learners should know," Journal of Dental Education, vol. 76, no. 11, pp. 1437-1442, 2012.

[34] W. C. Scarfe, A. G. Farman, and P. Sukovic, "Clinical applications of cone-beam computed tomography in dental practice," Journal of the Canadian Dental Association, vol. 72, no. 1, pp. 75-80, 2006.

[35] L. Palomo and J. M. Palomo, "Cone beam CT for diagnosis and treatment planning in trauma cases," Dental Clinics of North America, vol. 53, no. 4, pp. 717-727, 2009.

[36] D. Gutierrez, P. Monnin, J.-F. Valley, and F. R. Verdun, "A strategy to qualify the performance of radiographic monitors," Radiation Protection Dosimetry, vol. 114, no. 1-3, pp. 192-197, 2005.

[37] J. B. Ludlow and M. Ivanovic, "Comparative dosimetry of dental CBCT devices and 64-slice CT for oral and maxillofacial radiology," Oral Surgery, Oral Medicine, Oral Pathology, Oral Radiology and Endodontology, vol. 106, no. 1, pp. 930-938, 2008.

[38] T. M. De Araújo, M. H. A. Nascimento, and F. Bezzera, "Oral radiology: principles and interpretation," Revista Dental Press de Ortodontia e Ortopedia Facial, vol. 11, pp. 21-28, 2009.

[39] A. G. Farman, "Self-referral: an ethical concern with respect to multidimensional imaging in dentistry?" Journal of Applied Oral Science, vol. 17, no. 5, 2009.

[40] N. P. Lang, L. Pun, K. Y. Lau, K. Y. Li, and M. C. M. Wong, "A systematic review on survival and success rates of implants placed immediately into fresh extraction sockets after at least 1 year," Clinical Oral Implants Research, vol. 23, supplement 5, pp. 39-66, 2012. 

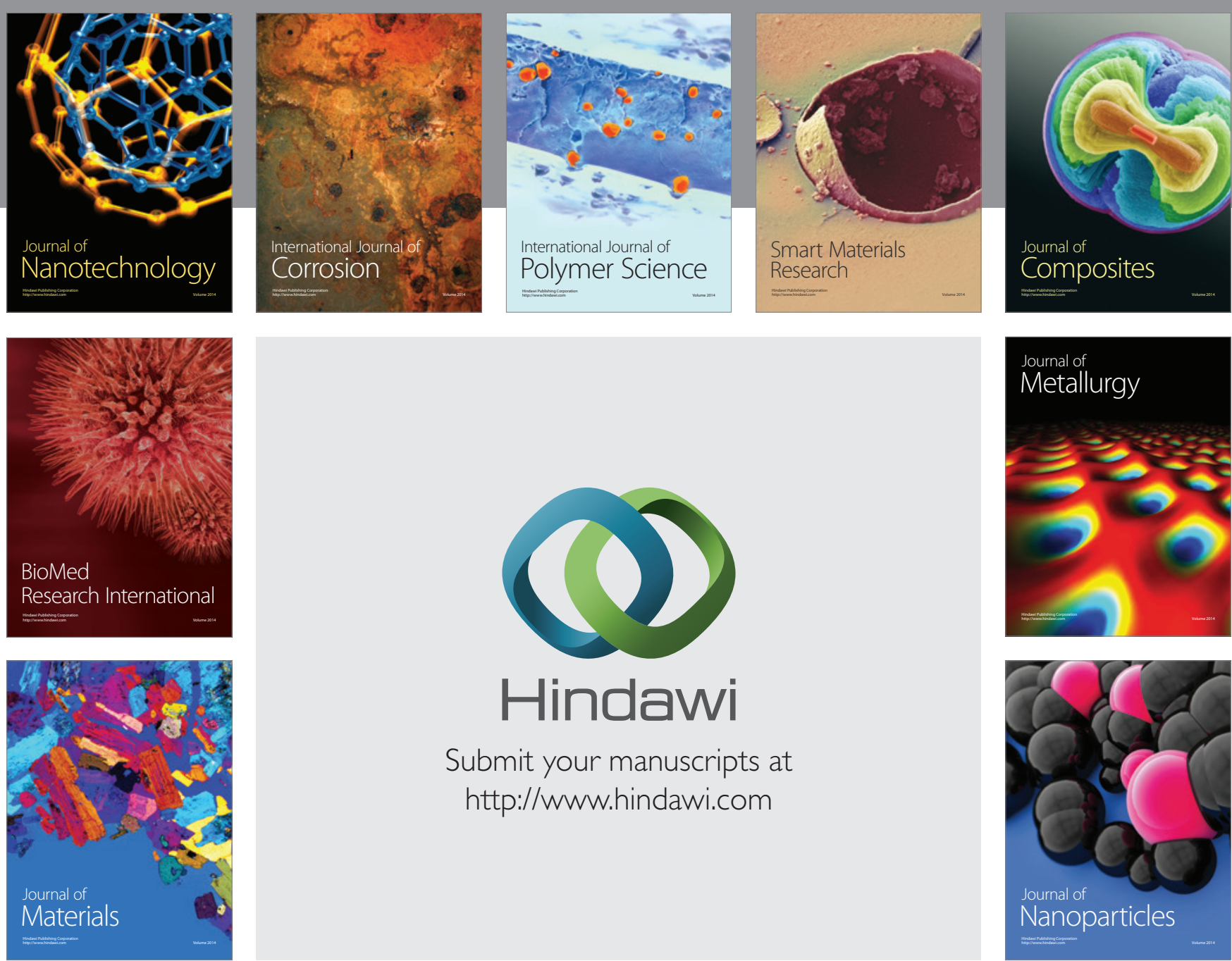

\section{Hindawi}

Submit your manuscripts at

http://www.hindawi.com

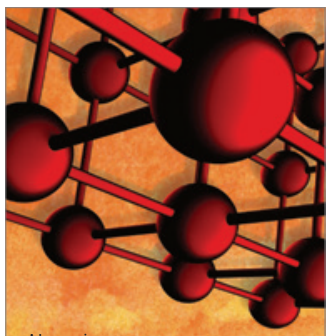

Materials Science and Engineering
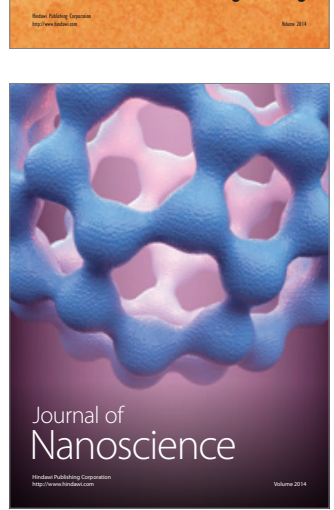
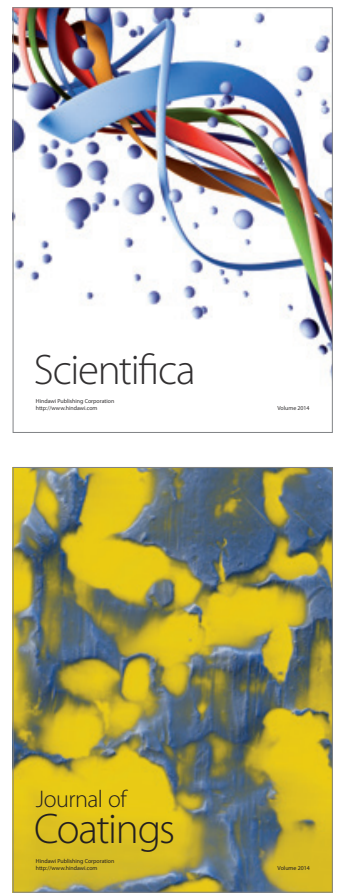
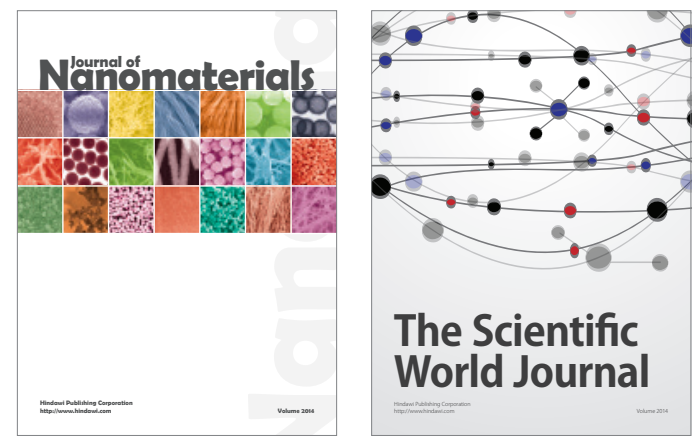

The Scientific World Journal
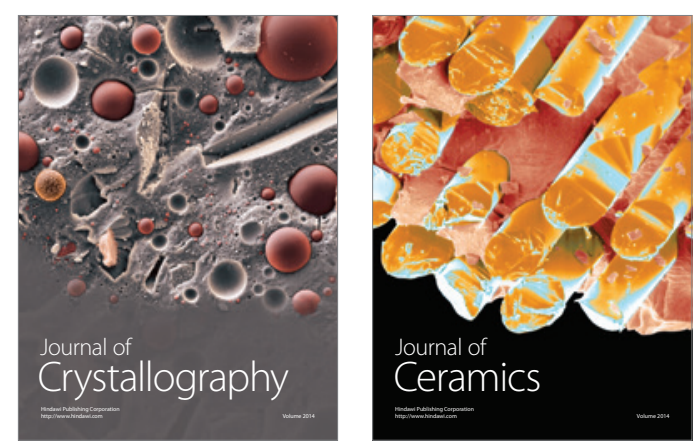
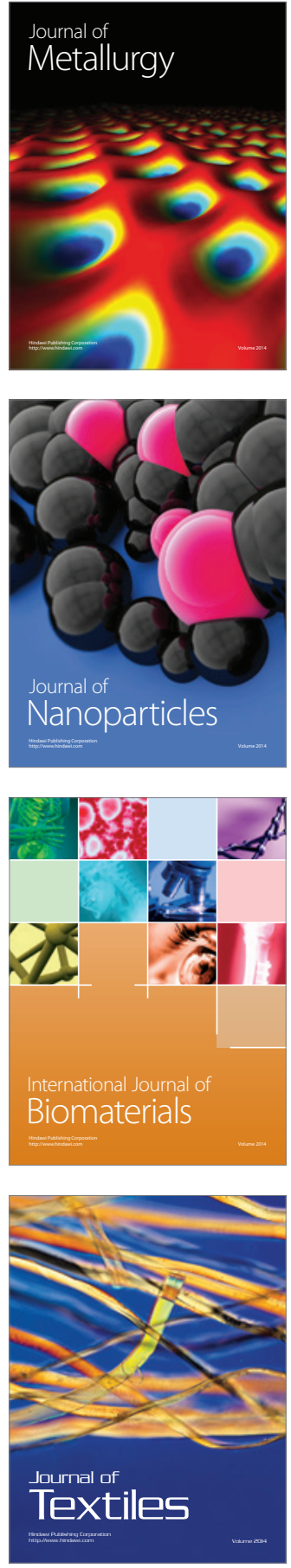